\title{
Weight Optimization of Rectangular Core Sandwich Panel using ANSYS
}

\author{
Anjan Kumar Nandi ${ }^{1}$, Hredey Mishra ${ }^{2}$ \\ ${ }^{I}$ (Dept. of Mechanical Engineering, JCOE, Kuran, India) \\ ${ }^{2}$ (Dept. of Mechanical Engineering, JCOE, Kuran, India)
}

\begin{abstract}
Research is going on for efficient design to reduce weight of load carrying platform or panel. Various types of designs are used for different applications. Our main aim is to design panel at which can carry load at min weight. By reducing weight we save material cost and also other cost. All steel sandwich panel can be effectively used for general purpose applications of load carrying platform. Various types of core (i.e. stiffener) is possible. In this paper we have used rectangular steel plate as core and top bottom facings are also steel plate. Here, we have designed and optimized sandwich panel having Imtr x 1mtr size for 1MT (10KN) load. We have discussed about important parameters of optimization for such panel and effect of change of these parameters on equivalent stress, total deformation and weight. It is found that stiffener height, stiffener thickness and no of stiffener are important parameters of weight optimization.
\end{abstract}

Keywords: Sandwich Panel, Weight Optimization, ANSYS, Static Analysis, Rectangular core

\section{Introduction}

A sandwich panel is a fabricated panel / structure that consists of two thin sheets joined to either side of a core stiffener. The separation of the facings by a lightweight core acts to significantly increase the second moment of area (and hence the bending stiffness) of the material cross-section with only a small increase in weight. There are following basic parts which are common-

- Top Facing Plate- Top layer of the panel, made of either metal or composite material.

- Bottom Facing Plate- Bottom layer of the panel, made of either metal or composite material

- Core -The part which joins top and bottom plate, may be metal composite or elastomer.

- Joining-Interface between the facings and core to transfers load from top to bottom plate

The material can be either regular, high tensile, stainless steel or aluminum alloys. By using steel we can obtain high strength at low cost compared to simple plate. By using aluminum alloys, composite material we can reduce weight even further but cost may be high. For general purpose application steel panel structures is a solution, because of its low cost even though weight may not be minimum as compared to panels of high aluminum or composite. Hence in our case structural steel is considered for analysis. In case of all steel sandwich panel, plates are used for top and bottom facing and plate or regular steel sections are used as core which is welded to the top and bottom plates. Typical construction of an all steel sandwich panel having rectangular core is shown in Fig. 1. In this paper we have analyzed square panels using rectangular steel plate as stiffener simply supported at two ends, other two ends free and concentrated load at center. Typical loading and support condition is shown in the Fig 2.

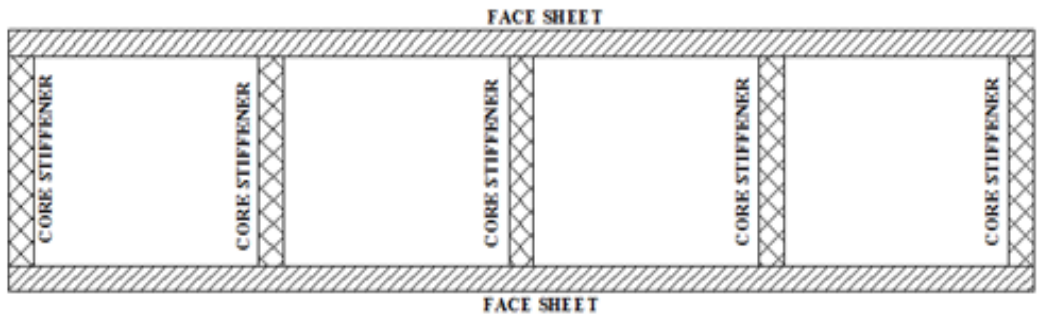

Fig.1: Typical All Steel Sandwich Panel

\subsection{Problem Statement:}

To design load carrying platform (panel) $1 \mathrm{mtr} \times 1 \mathrm{mtr}$, having rectangular steel plate used as core to carry a load of $10 \mathrm{KN}(1 \mathrm{MT})$ at centre of plate. 


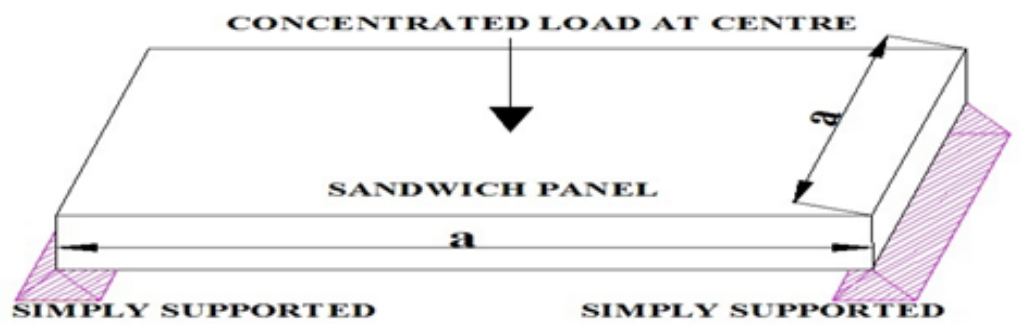

Fig.2: Typical Loading Condition

\subsection{Design criteria's are -}

- Material of construction- Structural Steel

- Max Equivalent Stress should be within allowable stress: $(0.6 *$ YST $=0.6 * 250=) 150 \mathrm{MPa}$

- Max Deflection should be within $0.5 \mathrm{~mm}$

- Weight should be minimum

- Support Condition : Simply supported at two sides other two sides free

We shall optimize the design by varying various design parameters of the panel namely- thickness of skin, stiffener size numbers and orientation.

\subsection{Objective-}

- The objective is Static Analysis of rectangular core sandwich panel.

- Find out stress variation with various parameters.

- Find out optimum design of panel for load condition mentioned above.

\subsection{Material Properties taken for ANSYS analysis-}

\section{Ansys Analysis}

Material properties used for ANSYS analysis are given in Table I.

TABLE I

MATERIAL PROPERTIES USED FOR ANSYS ANALYSIS

\begin{tabular}{|c|c|c|}
\hline 1 & Material & Structural Steel (IS 2062) \\
\hline 2 & Y.S. & $250 \times 10^{6} \mathrm{~N} / \mathrm{m}^{2}$ \\
\hline 3 & UTS & $410 \times 10^{6} \mathrm{~N} / \mathrm{m}^{2}$ \\
\hline 4 & Compressive & $500 \times 10^{6} \mathrm{~N} / \mathrm{m}^{2}$ \\
\hline 5 & Poisson's Ratio & 0.3 \\
\hline 6 & Young's Mod & $2 \times 10^{11} \mathrm{~N} / \mathrm{m}^{2}$ \\
\hline
\end{tabular}

Panel dimensions: $\quad$ Length $=$ Width $=\mathrm{a}=1000 \mathrm{~mm}$

Total load on plate $\quad \mathrm{w}=10 \mathrm{KN}$, Concentrated on center of top plate.

Support

Self-Weight:

Simply supported on two opposite edges other two edges free

Taken into account

\subsection{Tabulated Result of Analytical \& ANSYS Data:}

Following notations are used in tabulation-

$\mathrm{t}$ - Facing thickness; $\mathrm{t}_{1}$ - Stiffener thickness, $\mathrm{h}$ - Stiffener height, $\mathrm{n}$ - No of Stiffeners, $\sigma$ - Equivalent Stress / Von mises stress, $\delta$ - Total deformation, $w$ - Self weight of panel, Stiffener orientation longitudinal.

Initial ANSYS results for various facing \& stiffener thickness with fixed stiffener no, height and orientation are tabulated in Table-II.

TABLE II

RESULT OF ANALYTICAL \& ANSYS

\begin{tabular}{|c|c|c|c|c|c|c|c|c|c|c|}
\hline & Facing & \multicolumn{3}{|c|}{ Stiffener } & & & \multicolumn{3}{c|}{ \% Change in } \\
\hline Case & $\mathrm{t}$ & $\mathrm{t}_{1}$ & $\mathrm{~h}$ & $\mathrm{n}$ & $\sigma$ & $\delta$ & $\mathrm{w}$ & $\mathrm{w}$ & $\sigma$ & $\delta$ \\
\hline & $(\mathrm{mm})$ & $(\mathrm{mm})$ & $(\mathrm{mm})$ & $(\mathrm{Nos})$ & $\mathrm{MPa}$ & $\mathrm{mm}$ & $\mathrm{Kg}$ & $\%$ & $\%$ & $\%$ \\
\hline $\mathrm{I}$ & 3 & 3 & 20 & 5 & 186.73 & 2.89 & 49.4 & 0 & 0 & 0 \\
\hline II & 4 & 4 & 20 & 5 & 136.44 & 1.8502 & 66.14 & 34 & -27 & -36 \\
\hline III & 6 & 6 & 20 & 5 & 85.861 & 0.92752 & 98.71 & 100 & -54 & -68 \\
\hline IV & 8 & 8 & 20 & 5 & 59.995 & 0.54796 & 132.28 & 168 & -68 & -81 \\
\hline
\end{tabular}

Details of comparative variation with plate \& stiffener thickness is given in Table II. Graphical representation of comparative variation is given in Fig. 3. From the table and graph it is clear that, with increase 
of top \& bottom plate thickness stress \& deflection reduces but self-weight also increase. Increase of self-weight is very fast. Hence, we need to check other parameters for optimization.

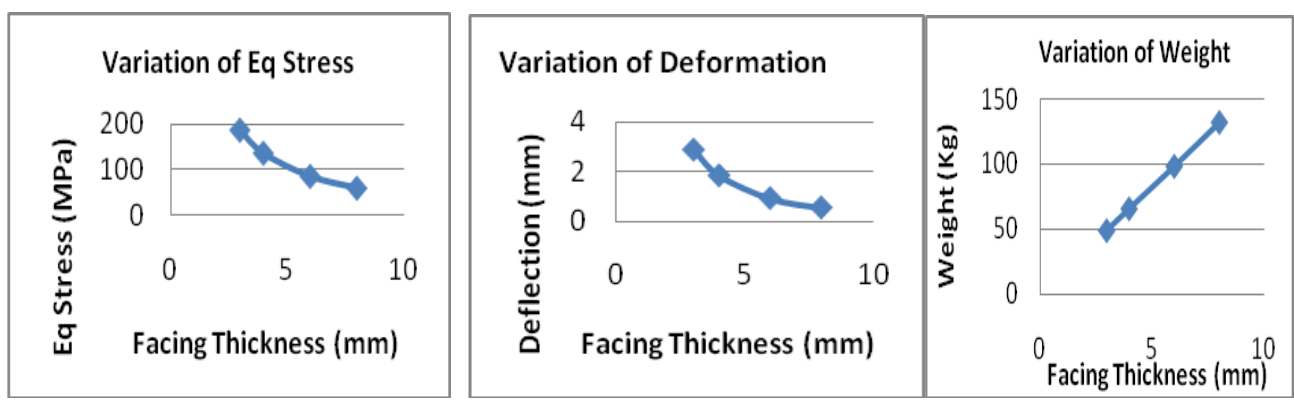

Fig.3: Graphical representation of variation of Equivalent Stress \& Deformation \& Weight with change of facing \& stiffener thickness

Typical ANSYS model and result of analysis for Case -II (facing thickness 4mm, stiffener thickness $4 \mathrm{~mm}$, stiffener height $20 \mathrm{~mm}$, no of stiffener 5 nos in longitudinal direction) is given in Fig. 4 \& Fig. 5 .
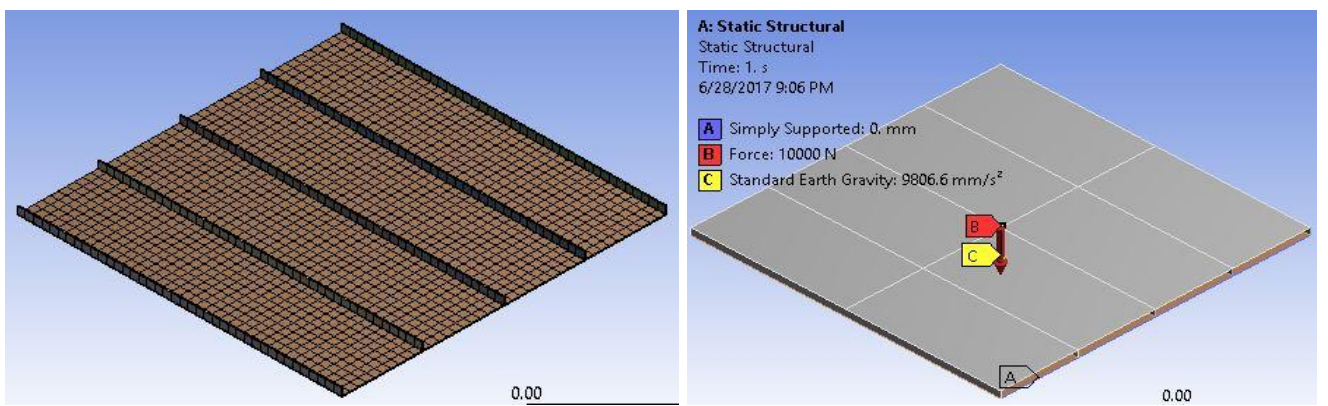

Fig.4: ANSYS analysis photo for mesh and loading \& support condition

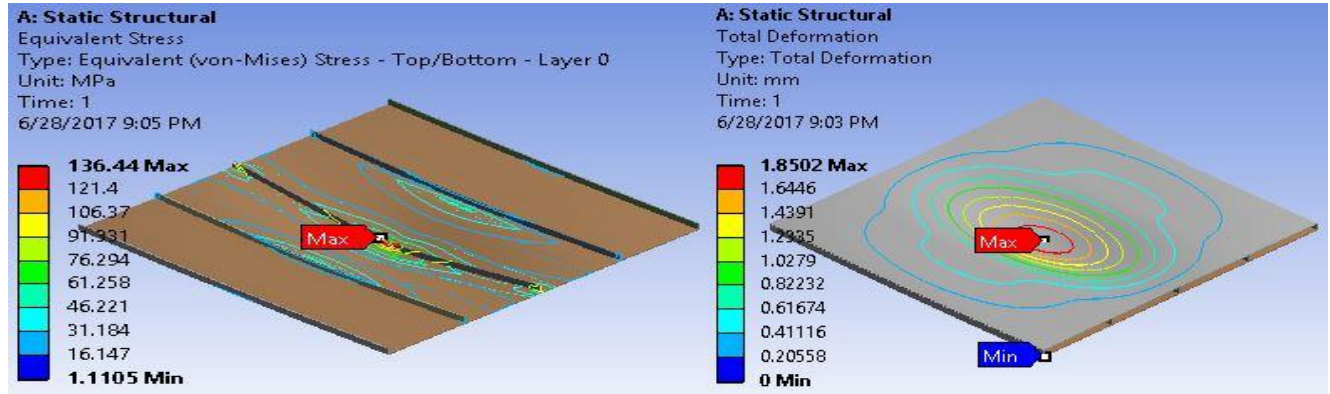

Fig.5: ANSYS analysis photo equivalent stress \& deformation

\section{Optimization}

For optimizing panel we need to finding out dimensions of panel having lowest possible weight which the criteria of acceptance i.e. allowable stress and deflection. To find out the parameters which need to be changed for optimization, we can look at basic strength of materials formulas for finding stress of a plate under bending load.

$$
\begin{aligned}
& \text { As per basic strength of material, bending stress of plate is given } \\
& { }_{\text {as }} \sigma=\frac{M}{I} *\left(1-v^{2}\right) * y \\
& \text { Where } \mathrm{M}=\text { Bending Moment, } \mathrm{I}=\text { Moment of Inertia of panel about neutral axis, } v=\text { Poisson's ratio }
\end{aligned}
$$




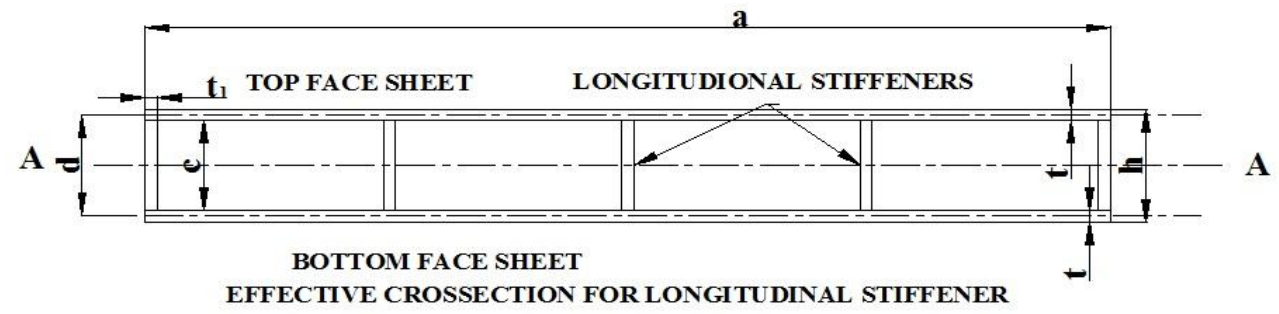

Fig.6: Effective cross section of panel

For longitudinal stiffeners in the sandwich panel loaded as per Fig 2, effective cross section is shown in the Fig 4. Moment of inertia of the effective section about central axis (A-A) can be calculated as follows:

$$
\begin{gathered}
\mathbf{I}_{\text {TOT }}=\left[\frac{\mathrm{bt}^{3}}{12}+(\mathrm{bt}) *\left(\frac{\mathrm{d}}{2}\right)^{2}\right] * 2+\frac{\mathrm{t}_{1} * c^{3}}{12} * \mathrm{n} \\
\mathbf{I}_{\text {TOT }}=\frac{\mathrm{bt}^{3}}{6}+\mathrm{bt} * \frac{\mathrm{d}^{2}}{2}+\frac{\mathrm{t}_{1} \mathrm{c}^{3}}{12} * \mathrm{n} \\
\text { Where } \quad d=\frac{1}{2}(c+2 t)
\end{gathered}
$$

From the above equations it is clear that to reduce stress we have to increase moment of inertia (MI). From above equation $1 \& 2$ it is clear that MI can be increased by increasing thickness of plate and stiffener, height of stiffener and no of stiffener. However any increase of those parameters will also increase weight. Hence optimization is required to find out best possible combination such that design criteria's are satisfied and also weight becomes min.

\subsection{Changing Height of Stiffener:}

ANSYS model is prepared for analysing the effect of change of stiffener height on equivalent stress and deflection. The model have thickness of facing and stiffener $4 \mathrm{~mm}$. Other parameters like height \& no of stiffeners are kept constant and height of stiffener varied from $20 \mathrm{~mm}$ to $60 \mathrm{~mm}$ in steps of $10 \mathrm{~mm}$. Result of ANSYS analysis is given in Table III. Variation of Weight, Equivalent stress and deflection with height of stiffener is given in Table III. Graphical representation of variation is shown in Fig. 6.

TABLE III

ANSYS ANALYSIS RESULT- WITH CHANGE OF STIFFENER HEIGHT

\begin{tabular}{|c|c|c|c|c|c|c|c|c|c|c|}
\hline \multirow{2}{*}{} & \multirow{2}{*}{$\mathrm{t}$} & \multicolumn{3}{|c|}{ Stiffener } & \multicolumn{2}{|c|}{ ANSYS } & \multicolumn{3}{c|}{ Change In } \\
\cline { 3 - 13 } & & $\mathrm{t}_{1}$ & $\mathrm{~h}$ & $\mathrm{n}$ & $\mathrm{w}$ & $\sigma$ & $\delta$ & $\mathrm{w}$ & $\sigma$ & $\delta$ \\
\hline & $\mathrm{mm}$ & $\mathrm{mm}$ & $\mathrm{mm}$ & $\mathrm{no}$ 's & $\mathrm{Kg}$ & $\mathrm{MPa}$ & $\mathrm{mm}$ & $\%$ & $\%$ & $\%$ \\
\hline $\mathrm{I}$ & 4 & 4 & 20 & 5 & 66.1 & 136.44 & 1.8502 & 0 & 0 & 0 \\
\hline $\mathrm{II}$ & 4 & 4 & 30 & 5 & 67.7 & 104.59 & 1.09 & 2 & -23 & -41 \\
\hline $\mathrm{III}$ & 4 & 4 & 40 & 5 & 69.3 & 100.61 & 0.72792 & 5 & -26 & -61 \\
\hline $\mathrm{IV}$ & 4 & 4 & 50 & 5 & 70.9 & 95.662 & 0.52682 & 7 & -30 & -72 \\
\hline $\mathrm{V}$ & 4 & 4 & 60 & 5 & 72.4 & 105.87 & 0.40558 & 10 & -22 & -78 \\
\hline
\end{tabular}
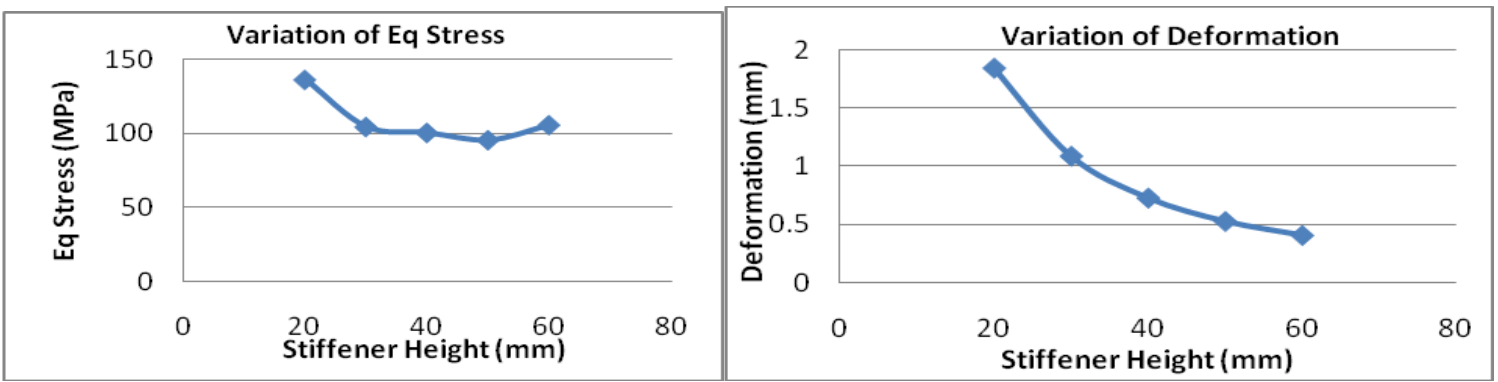

Fig. 6: Graphical representation of variation of Equivalent Stress \& Deformation with change of stiffener height 
From the above results it is clear that stiffener height is an important parameter for optimization as reduction in deformation much faster than increase in weight.

\subsection{Changing Thickness of Stiffener:}

ANSYS model is prepared for analysing the effect of change of stiffener thickness on equivalent stress and deflection. The model have thickness of facing $4 \mathrm{~mm}$ and stiffener height $50 \mathrm{~mm}$. Other parameters like facing thickness \& no of stiffeners are kept constant. Stiffener thickness varied from $03 \mathrm{~mm}$ to $08 \mathrm{~mm}$ in steps. Result of ANSYS analysis is given in Table IV. Variation of Weight, Equivalent stress and deflection with height of stiffener is given in Table IV. Graphical representation of variation is shown in Fig. 7.

TABLE IV ANSYS ANALYSIS RESULT - WITH CHANGE OF STIFFENER THICKNESS

\begin{tabular}{|c|c|c|c|c|c|c|c|c|c|c|}
\hline & $\mathrm{t}$ & \multicolumn{3}{|c|}{ Stiffener } & \multicolumn{3}{c|}{ ANSYS } & \multicolumn{3}{|c|}{ Change In } \\
\cline { 3 - 11 } & & $\mathrm{t}_{1}$ & $\mathrm{~h}$ & $\mathrm{n}$ & $\mathrm{w}$ & $\sigma$ & $\delta$ & $\mathrm{w}$ & $\sigma$ & $\delta$ \\
\hline & $\mathrm{m}$ & $\mathrm{mm}$ & $\mathrm{mm}$ & $\mathrm{no} / \mathrm{s}$ & $\mathrm{Kg}$ & $\mathrm{MPa}$ & $\mathrm{mm}$ & $\%$ & $\%$ & $\%$ \\
\hline I & 4 & 3 & 50 & 5 & 68.9 & 126.95 & 0.5845 & 0 & 0 & 0 \\
\hline II & 4 & 4 & 50 & 5 & 70.9 & 95.662 & 0.5268 & 5 & -28 & -34 \\
\hline III & 4 & 5 & 50 & 5 & 72.8 & 77.261 & 0.4909 & 8 & -42 & -38 \\
\hline IV & 4 & 6 & 50 & 5 & 74.8 & 65.345 & 0.4659 & 10 & -51 & -41 \\
\hline V & 4 & 8 & 50 & 5 & 78.7 & 55.137 & 0.4319 & 16 & -58 & -46 \\
\hline
\end{tabular}

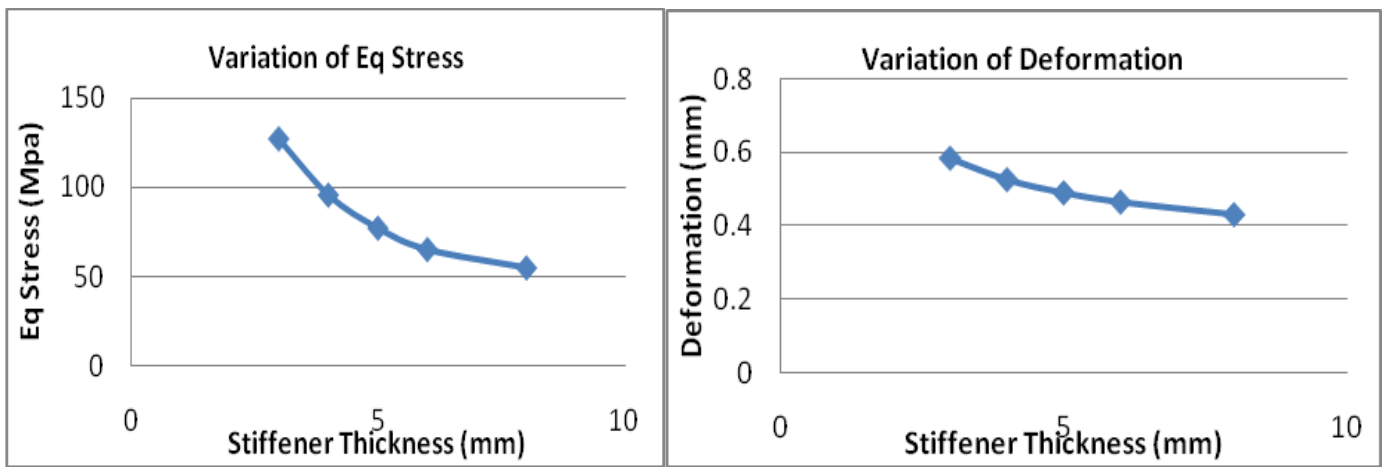

Fig. 7: Graphical representation of variation of Equivalent Stress \& Deformation with stiffener thickness

From the above results it is clear that stiffener thickness is an important parameter for optimization as reduction in stress \& deformation much faster than increase in weight.

\section{A. Changing no of Stiffener:}

ANSYS model is prepared for analysing the effect of change of stiffener thickness on equivalent stress and deflection. The model prepared on ANSYS have stiffener height 50mm. Other parameters like facing \& stiffener thickness are kept constant and no of stiffener varied from 03 to 11 in steps. Result of ANSYS analysis is given in Table V. Variation of Weight, Equivalent stress and deflection with height of stiffener is given in Table V. Graphical representation of variation is shown in Fig. 8.

Table V ANSYS Analysis Result - With change of Stiffener No

\begin{tabular}{|c|c|c|c|c|c|c|c|c|c|c|}
\hline \multirow{2}{*}{} & \multirow{2}{*}{} & \multicolumn{3}{|c|}{ Stiffener } & $\mathrm{w}$ & \multicolumn{2}{|c|}{ ANSYS } & \multicolumn{3}{|c|}{ Change In } \\
\cline { 3 - 12 } & & $\mathrm{t}_{1}$ & $\mathrm{~h}$ & $\mathrm{n}$ & & $\sigma$ & $\delta$ & $w$ & $\sigma$ & $\delta$ \\
\hline & $\mathrm{mm}$ & $\mathrm{mm}$ & $\mathrm{mm}$ & $\mathrm{no} ' \mathrm{~s}$ & $\mathrm{Kg}$ & $\mathrm{N} / \mathrm{mm} 2$ & $\mathrm{~mm}$ & $\%$ & $\%$ & \\
\hline I & 4 & 4 & 50 & 3 & 67.7 & 104.12 & 0.55718 & 0 & 0 & 0 \\
\hline II & 4 & 4 & 50 & 5 & 70.9 & 95.662 & 0.52682 & 5 & -8 & -5 \\
\hline III & 4 & 4 & 50 & 7 & 74 & 83.521 & 0.48637 & 9 & -20 & -13 \\
\hline IV & 4 & 4 & 50 & 9 & 77.1 & 75.146 & 0.4441 & 14 & -28 & -20 \\
\hline V & 4 & 4 & 50 & 11 & 80.3 & 74.631 & 0.40573 & 19 & -28 & -27 \\
\hline
\end{tabular}




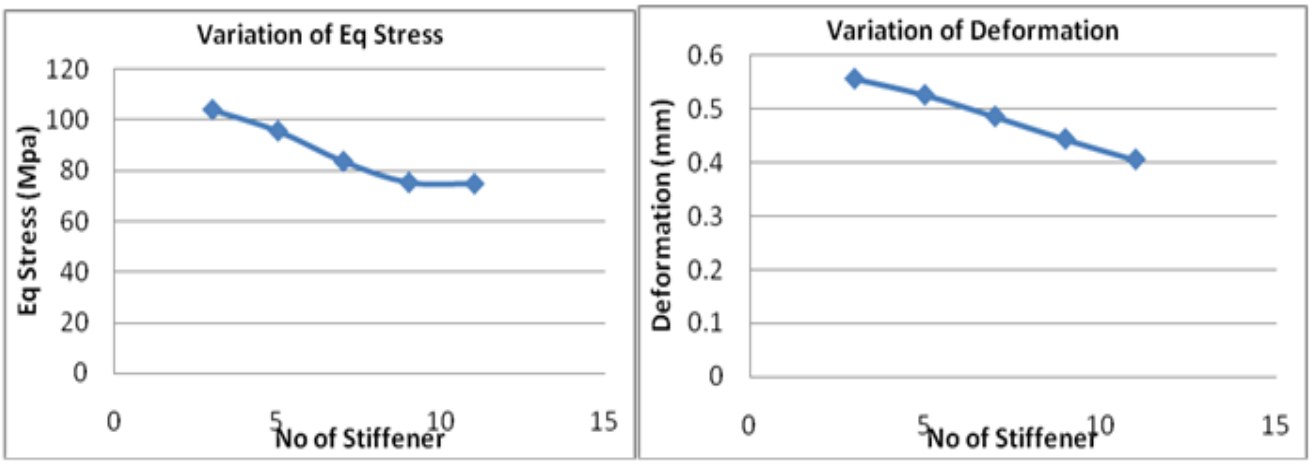

Fig. 8: Graphical representation of variation of Equivalent Stress \& Deformation with no of stiffener

From the above results it is clear that no of stiffener is an important parameter for optimization as reduction in stress \& deformation much faster than increase in weight.

\subsection{Final Model}

\section{Conclusion}

Based on above optimization following is the optimized model:

- Facing thickness $4 \mathrm{~mm}$, Stiffener $4 \mathrm{~mm}$ thick $50 \mathrm{~mm}$ height 7 nos in longitudinal direction.

- Equivalent stress $-83.5 \mathrm{MPa}$, Total deformation $-0.486 \mathrm{~mm}$

\subsection{Conclusions}

Following conclusions can be drawn from ANSYS analysis for optimization discussed above.

- Sandwich structure face thickness doubled then total deflection decreases $68 \%$ and equivalent stress decreases $54 \%$ but weight increased $100 \%$.

- If core stiffener height is doubled then Stress reduces by $26 \%$ and deformation reduces by $61 \%$ and weight increased by $5 \%$. However with increasing height effect of stress reduction becomes less and at some point it again starts increasing.

- With increase in height of stiffener stress and deflection reduces and this is very effective parameter for optimization and total deformation reduces at a faster rate than stress.

- With increase in height of stiffener stress and deflection reduces and this is effective parameter for optimization and equivalent stress reduces at a faster rate than total deformation

- If core stiffener thickness is doubled then Stress reduces by $51 \%$ and deformation reduces by $41 \%$ and weight increased by $10 \%$. However with increasing thickness of reduction of stress and deformation becomes lesser.

- If core stiffener no is increased by $66 \%$ then Stress reduces by $8 \%$ and deformation reduces by $5 \%$ and weight increased by $5 \%$. With increase in no of stiffener stress and deflection reduces at a faster rate than stress.

- With increase in no of stiffener effect of reduction of stress \& deflection gradually reduces.

- Increasing height of stiffener, thickness of stiffener \& no of stiffener are important factors in weight optimization.

During designing panel element for load carrying sandwich panel having rectangular plate as stiffener above optimization parameters are to be considered.

\section{References}

[1]. Stephen P. Timoshenko, S. Woinosky-Krieger,'Theory of plates and shells", Second Edition,McGraw Hill,1959

[2]. Richard G. Budynas, “Advanced Strength and applied stress analysis”, Second Edition.Mc Graw Hill, 1999

[3]. Patil, M.S., Date, D.D.and Ghalke, A.B., "Design And Analysis Of Light Weight Steel Sandwich Panels Using ANSYS Workbench", Indian Streams Research Journal, Dec 2005

[4]. V. Palanivelrajan, A.S. Selvakumar., "Design and analysis of corrugated sandwich Panel for structural applications", Indian Journal Of Applied Research, Volume:5 ,Issue:6, June 2015, ISSN - 2249-555X pp-674-677

[5]. Bagadi, Gopi Krishna; B. Rambabu, "Design and Analysis of Stainless Steel and Mild Steel Sandwich Composite Structure", IJMETMR Vol-2, April 2015, pp-624-632

[6]. Maiti S.K., “Advanced Strength of Materials”, NPTEL Video Lectures, CDEEP, IIT Mumbai, Lecture 34-36 